\title{
A Venture Capital Fund for Undergraduate Engineering Students at Rowan University
}

\author{
Anthony J. Marchese, Ph.D., John C. Chen, Ph.D. \& John L. Schmalzel, Ph.D. \\ School of Engineering \\ Rowan University
}

All engineering students at Rowan University are required to take the 8-semester Engineering Clinic sequence wherein multidisciplinary student teams engage in semester-long design projects. In addition to projects that are funded by local industry, faculty research grants or departmental budgets, a Venture Capital Fund has been created, which is specifically ear-marked for the development of original student inventions. Funding of up to $\$ 2500$ per student team per semester is competitively awarded based on student-generated proposals to the Venture Capital Fund, which has been created through a series of grants from the National Collegiate Inventors and Innovators Alliance (NCIIA). To qualify for funding, a multidisciplinary student team must propose, plan and implement an original, semester-long product development enterprise. To date, eleven projects have been funded through the Venture Capital Fund. This paper describes the results of several student entrepreneurial projects and compares the results of student surveys to assess the effectiveness of entrepreneurial projects in satisfying the technical objectives of the Engineering Clinic. The results suggest that students engaged in entrepreneurial projects devote more hours per week on their projects, have more "ownership" in their projects, and have a better understanding of the technical aspects and societal impact of their projects than their counterparts who are engaged in the more traditional engineering design projects.

\section{Presenters}

Anthony Marchese is an Associate Professor of Mechanical Engineering at Rowan University, where he has been since 1996. Marchese has a Ph.D. from Princeton University and holds B.S. and M.S. degrees from Rensselaer Polytechnic Institute in Troy, NY. He has also held positions in industrial and government laboratories at United Technologies Research Center in East Hartford, CT and NASA Lewis Research Center in Cleveland, $\mathrm{OH}$ and has two United States Patents. He is currently the national Chair of the Entrepreneurship Division at ASEE.

John Chen is an Associate Professor of Mechanical Engineering at Rowan University, where he has been since 1998. Prior to Rowan, he was a professor at North Carolina A\&T State University in Greensboro, NC. He received his B.S. in mechanical engineering from the University of Virginia in 1985, and his M.S. and Ph.D. degrees from Stanford University in 1987 and 1991.

John L. Schmalzel is the Chair of the Electrical and Computer Engineering program at Rowan University. Over the past five years, he has been active in the development of Rowan's Engineering Clinic curriculum. The upper division clinics provide a structure for multidisciplinary projects and entrepreneurship. His other interests include instrumentation and laboratory development. 


\section{Introduction}

In 1992, the local industrialist Henry M. Rowan made a \$100 million donation to the then Glassboro State College in order to establish a high-quality engineering school in southern New Jersey. This gift has enabled the university to create a bold, innovative and forward-looking engineering program. The College of Engineering at Rowan University is composed of four departments: Chemical Engineering (ChE); Civil and Environmental Engineering (CEE); Electrical and Computer Engineering (ECE); and Mechanical Engineering (ME). Each department has been designed to serve 25 to 30 students per year, resulting in 100 to 120 students per year in the College of Engineering. The size of the college has been optimized such that it is large enough to provide specialization in separate and credible departments, yet small enough to permit the creation of a truly multidisciplinary curriculum in which laboratory/design courses are offered simultaneously to all engineering students in all four disciplines. Indeed, the hallmark of the engineering program at Rowan University is the multidisciplinary, project-oriented Engineering Clinic sequence.

The Engineering Clinic is a course that is taken each semester by every engineering student at Rowan University. In the Engineering Clinic, which is based on the medical school model, students and faculty from all four engineering departments work side-by-side on laboratory experiments, design projects, applied research and product development. The following table contains an overview of course content in the 8-semester engineering clinic sequence. As shown in the table, while each clinic course has a specific theme, the underlying concept of engineering design pervades throughout $[1,2]$.

Table 1. The 4-year Engineering Clinic Sequence at Rowan University [3].

\begin{tabular}{|c|l|l|}
\hline Year & Fall & Spring \\
\hline Freshman & Engineering Measurements & NSF Competitive Assessment Laboratory \\
\hline Sophomore & $\begin{array}{l}\text { Total Quality Management / Technical } \\
\text { Writing }\end{array}$ & $\begin{array}{l}\text { Entrepreneurship / Public Speaking } \\
\text { Example Project: Guitar FX Pedal }\end{array}$ \\
\hline Junior & Multidisciplinary Design Projects & Multidisciplinary Design Projects \\
\hline Senior & Multidisciplinary Design Projects & Multidisciplinary Design Projects \\
\hline
\end{tabular}

The 4-year, 24-credit Engineering Clinic sequence offers students the opportunity to incrementally learn the science and art of design by continuously applying the technical skills they have obtained in traditional coursework. This just-in-time approach to engineering design education enables students to complete ambitious design projects as early as the sophomore year. And, by their junior and senior years, students are well equipped to embark on a completely original, entrepreneurial enterprise. This paper describes the ongoing results of an innovative venture capital system that allows students to competitively apply for funding opportunities to embark on such an enterprise. The Venture Capital Fund (VCF) was created by a series of grants from the National Collegiate Inventors and Innovators Alliance (NCIIA), an initiative of The Lemelson Foundation. 


\section{The Venture Capital Fund (VCF) at Rowan University}

The Junior and Senior Engineering Clinics feature a mixture of projects funded by industry and faculty research interests. Clearly, projects such as these are central to developing the design and problem solving skills that are lacking in the typical engineering curriculum. What is often missing, however, in the industry and faculty-created design projects, is the spirit of invention, innovation and entrepreneurship. One way to promote the entrepreneurial spirit is to provide students with the opportunity to propose their own original enterprises. Accordingly, we have created the Venture Capital Fund (VCF), specifically earmarked for the development of original products by multi-disciplinary student teams within the Junior and Senior Engineering Clinics [4,5].

Funding for student teams is competitively awarded based on student-generated proposals to the VCF. To be funded, a student proposal must describe an enterprise that meets the following criteria:

- The team must be multidisciplinary, including engineering students from at least two disciplines and, if possible, a student from outside engineering.

- The team must be organized into a company and must submit a business plan.

- The team must appoint a project director from the College of Engineering, an advisor from the College of Business, and an advisor from industry.

- The enterprise must consist of an original product idea that can be successfully designed, developed and prototyped in a single semester.

The latter criterion is possible given the unique set of rapid prototyping resources in place at Rowan University created in part by two separate NSF grants. The Competitive Assessment Laboratory (NSF DUE-9850563) features dedicated test stations for the complete engineering assessment of consumer products. Stereolithography: A Distributed Partnership (NSF DUE-9751651) has created a rapid prototyping center featuring a 3-D systems SLA-250 stereolithography machine, an Actua 2100 multi-jet modeling (MJM) rapid concept modeler, and a QuickCircuit rapid circuit prototyping machine. In addition to the externally funded projects described above, the College of Engineering has developed a state-of-the-art fabrication facility featuring advanced CNC and manual machine tools.

Each semester, the Junior and Senior Engineering Clinics have a total enrollment of approximately 200 students distributed equally from each of the four engineering disciplines. However, all of the students do not embark on an entrepreneurial endeavor as described above. The competitive VCF proposal process, which rewards only those with original and thoroughly planned ideas, requires a significant effort at the start of the semester. In short, it is much easier for students to get "hired" into an industry or faculty sponsored project. However, with the availability of real funding, and the prospect of managing their own funds for a semester, interested and committed students with good ideas and entrepreneurial spirit choose to submit proposals. Furthermore, as will be shown below, these students generally devote more time to their projects and, by their own assessment, are required to perform more in-depth engineering analysis than their counterparts who are engaged in faculty sponsored projects.

During the past 5 semesters, VCF proposals have been accepted from 11 multidisciplinary student teams. This figure represents approximately $7 \%$ of the roughly 150 Junior/Senior Clinic projects completed 
during this same period. In total, $17 \mathrm{ECE}$ students, $15 \mathrm{ME}$ students, $3 \mathrm{ChE}$ students and $4 \mathrm{CEE}$ students have participated in VCF projects. Several VCF projects, which are summarized in Table 2, will be described briefly in the following section.

Table 2. Projects funded to date by the Venture Capital Fund at Rowan University.

\begin{tabular}{|c|c|c|c|c|c|}
\hline & & & gineel & tuden & \\
\hline Project & Semester & CEE & ChE & ECE & ME \\
\hline Hurricane Roof Vent & Fall 1998 & 3 & 1 & & 1 \\
\hline Portable MP3 Player & Fall 1999 & & & 3 & 1 \\
\hline 3COM Palma RS232 Protocol Analyzer & Fall 1999 & & & 2 & 1 \\
\hline Automated Synchronized Spinning Exercise Cycle & Fall 1999 & & 1 & 2 & 1 \\
\hline Coating Thickness Monitor & Fall 1999 & 1 & & & 1 \\
\hline Linear Combination Guitar Effects Processor & Fall 1999 & & & 3 & 1 \\
\hline Hybrid Rocket Motor Demonstrator & Fall 1999 & & & 1 & 2 \\
\hline Dorm-Sized Air Conditioner & Fall 1999 & & 1 & 1 & 1 \\
\hline Enhanced Four-Wheel Drive Suspension & Fall 2000 & & & & 4 \\
\hline Home Theater GUI & Fall 2000 & & & 3 & \\
\hline Rescue Robot & Fall 2000 & & & 2 & 2 \\
\hline & $\begin{array}{r}\text { Total } \\
\text { Sum Total }\end{array}$ & 4 & 3 & 17 & $\begin{array}{l}15 \\
39\end{array}$ \\
\hline
\end{tabular}

\section{Portable MP3/CD Player}

Within the past several years, advances in digital signal processing techniques, miniaturization/ decreased costs of RAM and increased consumer access to the Internet have caused a stir within the music industry. With the MP3 file format it is now possible to store approximately 10 hours of music on one Compact Disk and, since each individual song file is approximately $4 \mathrm{MB}$ in size, these files can be readily downloaded from the Internet. While the latter activity is sometimes illegal, recording one's own CDs in MP3 format is not. Accordingly, there presently exists a rush to develop devices which capitalize on the MP3 technology.

As of Fall 1999, there were already several portable MP3 players on the market which enable the user to store MP3 files directly into RAM, resulting in 30 to 60 minutes of music. However, at that time, there had yet to be a portable device on the market that allowed the user to play CDs in multiple formats, including standard music CDs and CDs containing files in MP3 format. With this potential market in mind, a junior ME student assembled a team that included himself and two ECE students (one junior and one senior). 


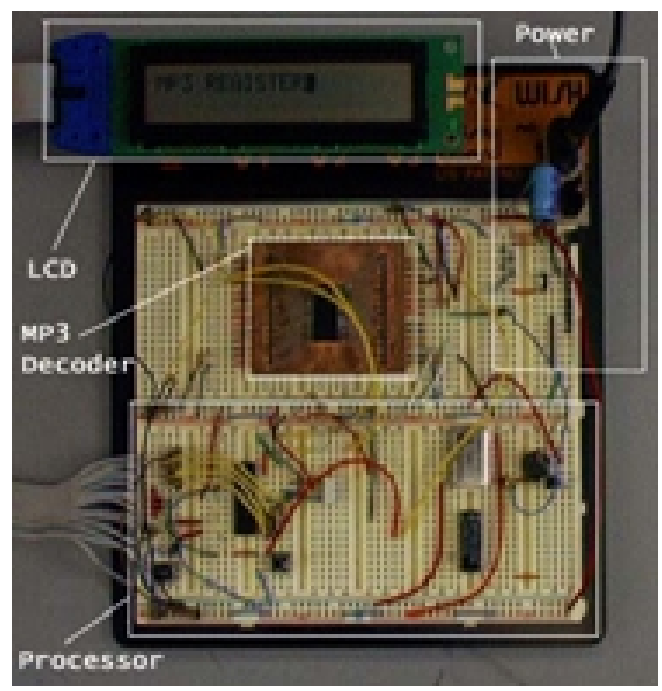

Figure 1. Prototype breadboard for portable MP3 player.

The above figure shows a version of a prototype breadboard circuit that the students built to learn how to communicate with the MP3 chip. The students acquired an MP3 decoder chip free of charge from the manufacturer and manufactured a printed circuit board using the QuickCircuit rapid circuit prototyping machine. The second figure is a Pro/ENGINEER assembly drawing of the MP3 player housing. The solid models were later imported to the 3D Systems stereolithography machine for rapid prototyping. A 240x122 dot matrix LCD display was also provided free of charge by a manufacturer. The Beta prototype is currently being built.

Unfortunately for the students, by late Fall 2000, there were several portable CD/MP3 players on the market. In this regard, the students learned the importance of rapid product development. In today's increasingly competitive environment, product development cycle times can no longer be measured in years. This is particularly true in the consumer electronics industry where a delay of one or two months can result in a product that is obsolete before it is even introduced. In this case, the students were not quick enough and they also learned the frustrations of not having the resources to compete with the large multinationals such as Phillips. Interestingly, during their attempt to be the first to market, the local media ran a newspaper article, which prompted calls from a local venture capitalist.

\section{Palm ${ }^{\circledR}$ RS232 Protocol Analyzer}

Personal Digital Assistants (PDAs) such as the Palm computing environment and the variety of Windows CE devices represent another quickly growing market, whose potential may have only scarcely been tapped. For several hundred dollars it is now possible to own a fully programmable computer with $8 \mathrm{MB}$ RAM and a graphical user interface that fits neatly in the palm of your hand. Apart from trying to reproduce typical desktop computing applications at a smaller scale, surprisingly few applications have been developed which take advantage of the mobile computing power available in the PDA environment. The field of instrumentation, for example, offers many potential applications that might take advantage of the PDA Computing platform

As an attempt to prove the capabilities of the PDA as an instrumentation platform, a team of two ECE students was awarded a VCF grant in Fall 1999 to develop an RS232 protocol analyzer using the Palm computing platform. Currently available serial protocol analyzers are generally outdated, bulky, 
cumbersome, and difficult to use. The goal of the student team was to make a more compact, less expensive, and easier-to-use product by taking advantage of the standardized interface of the Palm.

The students decided on designing and developing an RS232 serial port protocol analyzer because many electronic devices communicate via the RS232 serial port. However, most analyzers in existence are very large, and therefore difficult for field technicians to use. The Palm Pilot has built-in serial port, which made the development fairly straightforward.

To perform the project, the team purchased two Palm IIIx devices and a user license for the CodeWarrior Software which is used to program in the Palm computing platform. The students have found that the Palm IIIx provides enough computing power to create a viable instrumentation platform. Furthermore, serial data acquisition and viewing can be achieved with only a minimal amount of external circuitry. Developing this instrument will lay a foundation for further development of other instruments which will utilize the RS-232 port of the Palm.

\section{Coating Thickness Monitor}

One of the hallmarks of the Engineering Clinic is interfacing with local industry. In many cases, these relationships result in ideas for original and innovative products. In this particular case, an original product idea was generated from work with a local manufacturer of coated aluminum products. As part of their manufacturing process, the company must apply coatings to rolled aluminum in accordance with specifications provided by their customers. Current methodology used by the company is a destructive sampling process in which a 6"x12" sample is cut from the finished spool and its mass is measured. Both sides of the sample are then stripped of the coating and the mass is determined again. The difference in mass is defined as the amount of coating per square foot. From this information, a coating thickness can be determined.

This method lends itself to errors in the accuracy of the mass balance as well as human errors in the cleaning of the specimen. These errors are especially important since the average amount of coating per square foot of aluminum is only a few milligrams. Also, the coating thickness is determined after the coating has been applied to the entire roll. Thus, if the desired amount of coating is not present, the process must be repeated to insure the application of the proper amount of lubricant.

For this project, a faculty member charged a student team to develop a method to nondestructively monitor the thickness of the coating as the aluminum is being rolled. In response, the team was rewarded with a VCF grant in Fall 1999. The team consisted of two junior Mechanical Engineering students, one junior Civil and Environmental Engineering student and one senior Electrical and Computer Engineering student. In the proposed device, real time data of the coating thickness along the whole length of the spool will be provided, instead of just a measure of a small portion at the end of the spool. This will allow for adjustments to be made in the amount of lubricant applied to the aluminum it is being coated. Ultimately, this device will save the company precious manufacturing time and provide a more accurate assessment of the distribution of lubricant on the aluminum. 
After examining four possible methods for monitoring the coating thickness, the students chose an optical method. This method determines the thickness of the coating by utilizing the reflections of a laser. In this method, a laser will project two reflections. Ideally, one beam will reflect off the top of the coating and the other off the top of the aluminum. The two reflections will then be detected by two photo diodes, denoted on the schematic below as detectors. These detectors will then determine the distance between the reflections.

\section{Linear Combination Guitar Effects Pedal}

In the Spring 1999 Sophomore Engineering Clinic, 35 students took part in a guitar effects pedal product development project. The students were organized into 9 separate companies. In 16 weeks, each company designed, developed, tested and manufactured a fully operational and market-ready prototype. As shown below, the prototypes were manufactured using stereolithography and rapid circuit prototyping along with commercial-off-the-shelf components.

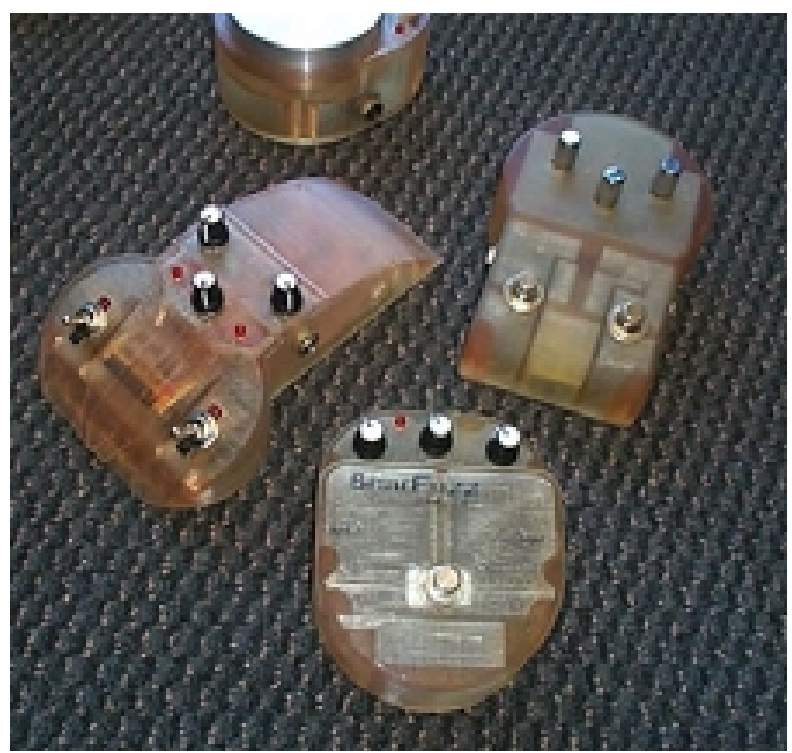

Figure 2. Guitar effects pedals from Spring 1999 Sophomore Engineering Clinic.

While working on their sophomore audio development project, a group of three junior ECE students and one junior ME student uncovered a potential market for an innovative, yet simple and cost effective product. The product combines multiple effects in a way that allows the player to control the magnitude of each effect at all times. In current multi-effects processors, the magnitude of each effect is preprogrammed and each effect is simply turned on and off. The student design takes away the need for preprogramming these settings.

For the initial prototype, the students focused on combining two of the most popular guitar effects: distortion and chorus. The human interface is a single foot switch, which controls the multiple effects. If force is applied to the far right side of the switch, the device will produce $100 \%$ distortion. If force is applied half way to the right, then the effects processor will produce $75 \%$ distortion and $25 \%$ chorus. If force is applied to the center of the switch, the processor will produce $50 \%$ distortion and $50 \%$ chorus. 
The switch functionality is mirrored for the left or chorus side of the button.

\section{The Fan Conditioner: A Dormitory Sized Air Conditioner}

College dormitory rooms often become extremely hot during early fall and late spring months. This discomfort can make it difficult for the occupant to sleep well or carry out his/her daily activities. However, because of school power restrictions, residents are not permitted to use window mounted air conditioning units, which would typically require approximately 1000 Watts. Students are forced to use traditional fans as their only method of air circulation and cooling. Fans merely circulate the hot air around the room without decreasing the temperature of the air.

To satisfy this need, a team consisting of one senior ME student, one junior ChE student and one junior ECE student decided to design and develop a low-cost, low-power, dormitory-sized air-cooling device. The goal was to tap into the vast market of college students who are not permitted to use air conditioners in their dorm rooms and cannot afford other similar products in the market.

Research showed that the average dormitory has approximately two fans per student. The students probably spend approximately 30 dollars per fan, yet these devices do not solve the temperature problem. In a search of the prior art, the team members found several patented products that used evaporative cooling. However, these devices sold for $\$ 100$ to $\$ 150$ dollars.

After conducting experiments and or theoretical calculations on evaporative cooling technique, open loop water cooling, closed loop water cooling and vapor-compression refrigeration, the students decided to focus on a closed loop water-cooled heat exchanger system. The system is currently under development.

\section{The Articulating Lift Block: An Enhanced 4-Wheel Drive Suspension Device}

The majority of all mid-priced sport utility vehicles (SUVs), trucks, and even some vans sold in today's market have a suspension which consists of leaf springs with solid axles as opposed to air, independent, coil spring or torsion bar suspension systems. This is a result of the relative low cost and adequate support offered by a spring leaf suspension in comparison to higher priced independent suspensions that can be found on the higher priced SUVs and trucks on the market.

One of the major design characteristics of a suspension with leaf springs and solid axles is the unnecessary presence of torsional stresses that are produced in certain driving situations. The specific situation that causes these unnecessary torsional stresses in a leaf spring suspension occurs when the leaf spring is oriented in an off-camber-driving situation. This situation occurs frequently in any SUV or offroad pickup when driving on any type of off-road setting. The torsional stresses are a direct result of the suspension compression at one end of the axle and the suspension droop on the opposite end of the axle. With the leaf springs solidly clamped to the outer housing of the axle, the springs do not have the degrees of freedom required to avoid the torsional stresses placed on them. This is a recurring problem for any leaf spring suspension SUV or off-road pickup that is constantly subjected to off-road driving situations in which the driving surface is filled with rises and dips. 
The constant application of unnecessary torsional stresses to the leaf springs degrade their mechanical integrity and ultimately affect the overall performance and longevity of the vehicle's suspension system. Elimination of the torsional stresses would not only improve the performance of the leaf springs but also the longevity of use. Accordingly, a junior student from the Department of Mechanical Engineering proposed an original design to eliminate torsional stress in the leaf springs. To develop this product, the student assembled a team of $4 \mathrm{ME}$ students.

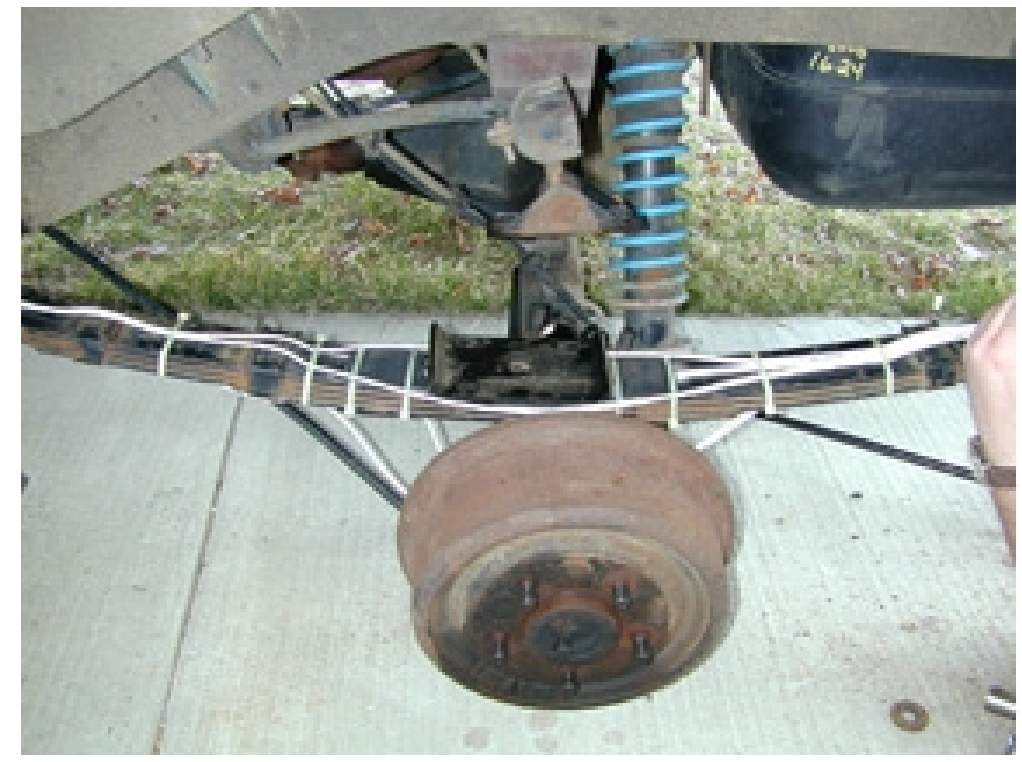

Figure 3. Strain gauge testing of an SUV leaf spring fitted with the Articulating Lift Block.

The product will be incorporated into an after-market lift kit, which is a common device employed by SUV and off-road pickup owners to lift their suspension. Reasons for lifting the suspension include both greater ground clearance and increased room for larger tires. Both of these applications are useful to anyone who is an off-road enthusiast, and it also makes the vehicle look better. A standard lift kit comes with $\mathrm{U}$ bolts and lifting blocks.

Like a standard lift kit, the original student design is intended for aftermarket use as a complementary item that would work just like a lift kit but with the elimination of torsional stresses that are created with a standard lift kit. The articulating lift block is designed to reduce torsional strain on the leaf springs of a live axle suspension system, while at the same time improving the overall flexibility of the vehicle's entire suspension system. The device must also be durable enough to handle the rigors of off-road use.

In Fall 1999, the students designed and built a prototype of their lift block. The majority of the design components were purchased from various vendors. The only parts of the design that required machining were the upper and lower parts of the housing block. The parts were machined manually using a vertical milling machine.

Having designed and built the prototype, the students embarked on a rigorous testing schedule in which they tested both the bi-directional strain of the leaf springs and the flexibility of the entire suspension. 
These tests were performed with the test vehicle, a 1997 Jeep Cherokee Sport, in three stages of suspension development. Stage 1 testing was in stock form, stage 2 testing was with a standard 3" lift installed (front coil spacers \& rear blocks) and Stage 3 was with the articulating lift blocks replacing the standard blocks in the rear. Bi-directional strain gauges were mounted to the top and bottom surfaces of the upper- and lowermost leaves, respectively, in each spring pack, both fore and aft of the axle. Eight bidirectional strain gauges, for a total of 16 channels, were used to take strain data from the leaf springs in the rear suspension of the Cherokee during both modes of vehicle testing, static and dynamic. Static tests were done using a forklift and dynamic testing was done on highway and city driving. Figure 3 shows the strain gauge installation for the static testing.

The completed prototype is currently installed in the project leader's Jeep Cherokee, where he continues to compile test mileage. The project is now in the parametric design phase, in which some minor design parameters are being optimized.

\section{Hurricane Roof Vent}

In Fall 1998, after a review of the submitted proposals, the first VCF award of $\$ 2500$ was given to a multidisciplinary team of engineering students to develop their original idea of a pressure relief system to prevent residential roof damage during high wind loading. The project was proposed by two Civil Engineering students who assembled a team that included students from Mechanical Engineering and Chemical Engineering. As part of the development project, students performed wind tunnel testing with scale models developed using stereolithography. The students also modeled the flow of air over (and into) a house during high speed wind loading using the computational fluid dynamics code FLUENT, and have built a full-scale pressurized test bed to develop the pressure relief mechanism.

The original idea for the project was developed by a Rowan civil engineering student during a summer internship at a local civil engineering firm. Through on-the-job research and investigation he came upon the idea for the Hurricane Roof Vent, which seemed like an obvious solution to the serious problem of roof damage during high speed wind loading. Upon his return to class in Fall 1998, he decided to pursue his idea and submit a proposal to the venture capital fund described above. As part of his proposal, he formed a strong and multidisciplinary group consisting of three students from the Department of Civil Engineering and one each from the Departments of Chemical Engineering and Mechanical Engineering. The proposal was not only original, but very well written and thoroughly researched. The students were funded for the fully requested amount of $\$ 2500$.

To perform the required analysis, the chemical engineering student was charged with modeling the fluid mechanics using FLUENT. A civil engineering student and a mechanical engineering student were put in charge of wind tunnel testing. This task involved developing 3-D solid models using Pro/Engineer, manufacturing the models using stereolithography, instrumenting the models with manometers and testing them in a 12"x12" 0-100 MPH wind tunnel. The two remaining civil engineering students focused on design and construction of a full scale prototype of the roof vent. 
To better understand the fluid mechanical mechanisms of roof damage and to determine the required vent area, the flow of air over and into a house during high wind conditions was modeled using the commercial CFD code FLUENT. There are several possible mechanisms for roof damage during high winds. The first mechanism is caused by the flow of wind over the roof, creating local negative pressures above the roof. The second mechanism is caused by flow of air into the house (for example, through broken windows), creating a positive pressure below the roof. In either case, the pressure gradient between the inside and outside of the house can potentially create forces strong enough to cause severe structural damage.

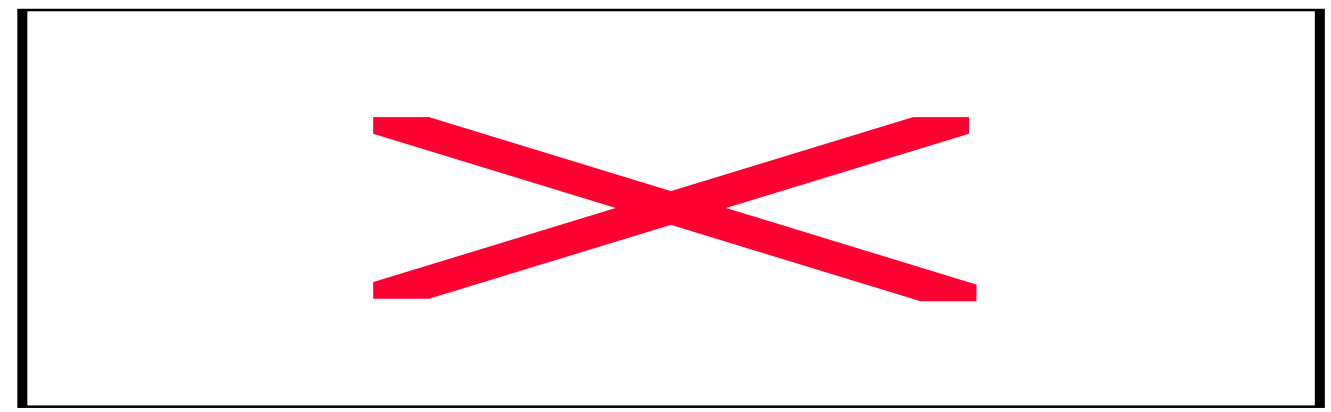

Figure 4. Predicted pressure contours from CFD model of a $100 \mathrm{MPH}$ wind flow over a roof.

A shown in Figure 4, for a wind loading of $100 \mathrm{MPH}$, it is evident that the highest pressure is located on the supporting wall of the windward side of the house and the lowest pressure is located on the windward exterior face of the roof. Assuming that the pressure within the house remained at atmospheric conditions, the pressure differential created by merely the flow over the roof might be great enough to cause the roof to tear free from the remaining structure. Further simulations (not shown) were performed for conditions in which the integrity of the windward side of the house was broken (i.e. a window was broken). These results showed an even higher pressure difference across the roof due to a positive pressure within the house.

As a second means of determining the possible pressure difference on a roof in a hurricane, experimental data were obtained from two separate scale models mounted in a wind tunnel. The model was oriented so that the wind flowed normally to the ridge along the top of the roof. Values for "model pressures" were measured in inches of water. Through scaling, the experimental measurements were used to calculate actual pressure differences over a full size roof. 


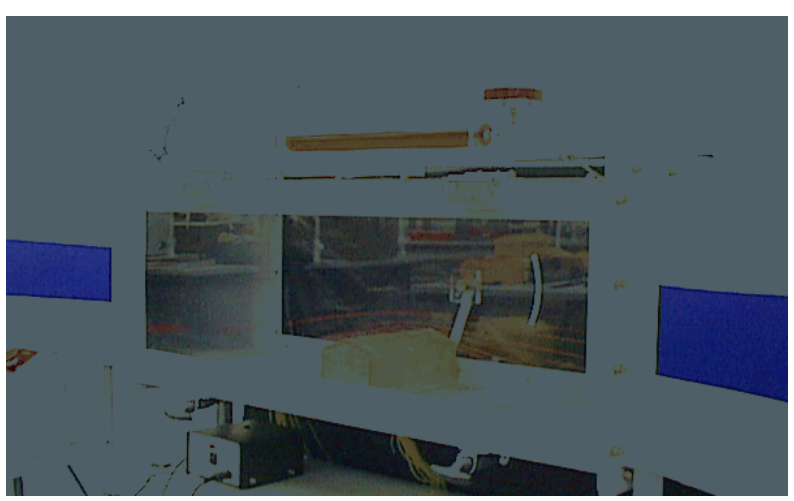

Figure 5. Wind tunnel models in test configuration.

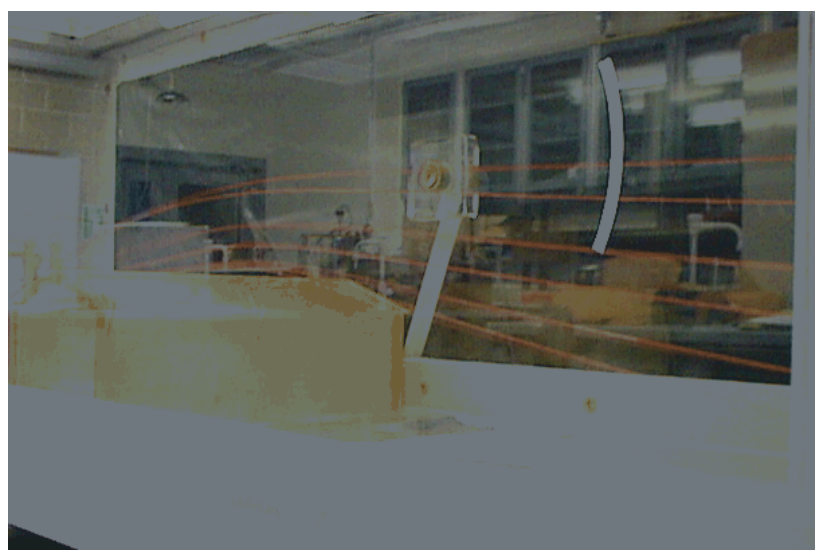

To expedite the process, Pro Engineer was used to generate 3-D solid models of the wind tunnel scale models. The scale models were $1 / 50^{\text {th }}$ the size of a standard house with a four to twelve pitch roof. The first was air tight, allowing no wind into the house. This model was used to measure the negative pressures on the outside of the roof. Eight holes were placed from front to back along one edge of the house and another eight from front to back along the middle. A second model was built, identical to the first, but with a square hole on the windward wall equal to two percent of the total surface area of the wall. This hole was positioned in the center of the windward wall to provide symmetry, which would aid in the assumptions about pressures on both edges. The 3D solid models created using Pro/Engineer were manufactured using a 3-D Systems SLA-250 stereolithography machine. By using stereolithography to build the scale models, it was possible to manufacture each part with all of the pressure taps built in.

The key to a successful invention is to determine the potential market as early as possible. In the case of the Hurricane Roof Vent, the students had to decide whether the product would be an "after market" item that could be retrofitted into any existing residential roof, or a product that could only be installed in new home constructions. As a first approach, the students chose the former embodiment. Accordingly, for their design to be seriously considered, it would have to be able to fit into the existing truss system of the typical roof. In addition, the retrofit would need to completely weatherproof. Given these constraints, the students built a full-scale, pressurized test bed consisting of a section of roof. Using this test bed, the students had the ability to test various configurations of the roof vent for sealing and venting capability. The majority of the materials for the test bed were purchased at Home Depot using funds from the NCIIA grant. To generate the pressure differential across the roof, a high-pressure blower was purchased. The test bed was instrumented with a pressure transducer and tests were conducted to determine the pressure differential required to open the vent. 
In two semesters, the students were able to perform wind tunnel testing, computer simulation and fabrication of a test bed to aid in the design of their original invention. The students have since graduated and will most likely not continue work on this project.

\section{Assessment}

The major goal of the VCF projects is to provide a venue for students with an entrepreneurial spirit to explore their new ideas. This objective is easily assessed and, as would be expected, the results show that the VCF concept is clearly effective in this regard. However, since the VCF projects are completed within the Junior/Senior Engineering Clinic they must satisfy a list of other objectives as well. To assess whether the VCF projects satisfy the objectives of the Junior/Senior Clinic, student surveys have been compiled for both the VCF projects and the standard projects. To date, there have been approximately 150 projects, 11 of which have been VCF projects. The results of the student surveys are discussed in this section.

The objectives of the Junior/Senior Engineering Clinic have been developed by all four engineering programs at Rowan in concert with the new ABET 2000 guidelines. At the conclusion of the course, students are expected to:

- Demonstrate expanded knowledge of the general practices and the profession of engineering

- Demonstrate an ability to work effectively in a multidisciplinary team.

- Demonstrate acquisition of new technology skills through use or development of appropriate computer hardware, software, and/or instrumentation.

- Demonstrate business and entrepreneurial skills by developing a business plan, market plan, venture plan, or other approved instrument.

- Demonstrate effective use of project and personnel management techniques.

- Identify and meet customer needs.

- Integrate engineering professionalism and ethics in their work and as it relates to the context of engineering in society.

- Demonstrate improved communication skills, including written, oral, and multimedia.

- Conduct a patent search and, if applicable, write a patent disclosure for novel work.

To assess whether these objectives are being achieved, an on-line survey is given to students at the end of each semester of their 4-semester Junior/Senior Engineering Clinic Sequence. Tables 3 and 4 contain a list of selected survey questions that were used as part of the present study to compare the effectiveness of VCF projects with respect to all other projects conducted during the 5-semester period of this study.

Table 3 contains the results of the survey for all non-VCF projects completed during this period, while Table 4 contains the results of the survey for all VCF projects completed during this period. The results of both surveys are discussed below. 
Table 3. Selected questions and survey results from the Junior/Senior Engineering Clinic survey for all non-VCF projects.

\begin{tabular}{|c|c|c|c|c|c|}
\hline \multirow{2}{*}{\begin{tabular}{|l} 
Question \\
$\begin{array}{l}\text { 1. To what degree were the technical skills learned in your major } \\
\text { coursework used effectively in your projects? }\end{array}$
\end{tabular}} & \multicolumn{5}{|c|}{ Rating Scale : and Results } \\
\hline & $\begin{array}{c}\text { Ineffectively } \\
3 \% \\
\end{array}$ & $\begin{array}{c}\text { Effectively to } \\
\text { Moderately } \\
4 \% \\
\end{array}$ & $\begin{array}{c}\text { Moderately } \\
23 \% \\
\end{array}$ & $\begin{array}{c}\text { Effectively } \\
38 \% \\
\end{array}$ & $\begin{array}{c}\text { Very } \\
\text { Effectively } \\
32 \% \\
\end{array}$ \\
\hline $\begin{array}{l}\text { 2. How many engineering disciplines were required to complete } \\
\text { your project? }\end{array}$ & $\begin{array}{c}\text { Within one } \\
\text { discipline } \\
17 \%\end{array}$ & $\begin{array}{c}\text { Mostly within } \\
\text { one discipline } \\
36 \%\end{array}$ & $\begin{array}{c}\text { Two } \\
\text { Disciplines } \\
25 \% \\
\end{array}$ & $\begin{array}{c}\text { Three } \\
\text { Disciplines } \\
6 \% \\
\end{array}$ & $\begin{array}{c}\text { Four } \\
\text { Disciplines } \\
16 \% \\
\end{array}$ \\
\hline $\begin{array}{l}\text { 3. What is the probability that your engineering clinic project } \\
\text { could be the basis for a new process or product? }\end{array}$ & $\begin{array}{l}\text { Low } \\
12 \% \\
\end{array}$ & $\begin{array}{c}\text { Low to } \\
\text { average } \\
6 \%\end{array}$ & $\begin{array}{c}\text { Average } \\
28 \% \\
\end{array}$ & $\begin{array}{c}\text { Average to } \\
\text { high } \\
48 \%\end{array}$ & $\begin{array}{l}\text { High } \\
7 \% \\
\end{array}$ \\
\hline $\begin{array}{l}\text { 4. Assess your leadership and project management skills: } \\
\text { a. Before taking this course }\end{array}$ & $\begin{array}{l}\text { Poor } \\
1 \%\end{array}$ & $\begin{array}{l}\text { Fair } \\
1 \%\end{array}$ & $\begin{array}{c}\text { Average } \\
42 \%\end{array}$ & $\begin{array}{l}\text { Good } \\
48 \%\end{array}$ & $\begin{array}{c}\text { Excellent } \\
7 \%\end{array}$ \\
\hline b. After taking this course. & $\begin{array}{l}\text { Poor } \\
0 \% \\
\end{array}$ & $\begin{array}{l}\text { Fair } \\
1 \% \\
\end{array}$ & $\begin{array}{c}\text { Average } \\
16 \% \\
\end{array}$ & $\begin{array}{l}\text { Good } \\
64 \% \\
\end{array}$ & $\begin{array}{c}\text { Excellent } \\
19 \% \\
\end{array}$ \\
\hline $\begin{array}{l}\text { 5. Assess your effort expended on the following activities: } \\
\text { a. Literature review / Research }\end{array}$ & $\begin{array}{l}\text { Low } \\
1 \%\end{array}$ & $\begin{array}{c}\text { Low to } \\
\text { moderate } \\
10 \%\end{array}$ & $\begin{array}{c}\text { Moderate } \\
28 \%\end{array}$ & $\begin{array}{c}\text { Moderate to } \\
\text { high } \\
42 \%\end{array}$ & $\begin{array}{l}\text { High } \\
19 \%\end{array}$ \\
\hline b. Application of engineering theory and/or design calculations. & $\begin{array}{l}\text { Low } \\
3 \% \\
\end{array}$ & $\begin{array}{c}\text { Low to } \\
\text { moderate } \\
3 \%\end{array}$ & $\begin{array}{c}\text { Moderate } \\
27 \% \\
\end{array}$ & $\begin{array}{c}\text { Moderate to } \\
\text { high } \\
47 \%\end{array}$ & $\begin{array}{l}\text { High } \\
21 \% \\
\end{array}$ \\
\hline $\begin{array}{l}\text { c. Use of advanced engineering software (Pro/E, Fluent, } \\
\text { HYSYS, etc.) }\end{array}$ & $\begin{array}{l}\text { Low } \\
17 \%\end{array}$ & $\begin{array}{c}\text { Low to } \\
\text { moderate } \\
17 \%\end{array}$ & $\begin{array}{l}\text { Moderate } \\
11 \% \\
\end{array}$ & $\begin{array}{c}\text { Moderate to } \\
\text { high } \\
11 \%\end{array}$ & $\begin{array}{l}\text { High } \\
35 \%\end{array}$ \\
\hline d. Laboratory experiments and/or fabrication and testing & $\begin{array}{l}\text { Low } \\
2 \%\end{array}$ & $\begin{array}{c}\text { Low to } \\
\text { moderate } \\
2 \% \\
\end{array}$ & $\begin{array}{c}\text { Moderate } \\
10 \% \\
\end{array}$ & $\begin{array}{c}\text { Moderate to } \\
\text { high } \\
18 \%\end{array}$ & $\begin{array}{l}\text { High } \\
69 \% \\
\end{array}$ \\
\hline e. Creative thinking and problem solving & $\begin{array}{l}\text { Low } \\
0 \% \\
\end{array}$ & $\begin{array}{c}\text { Low to } \\
\text { moderate } \\
0 \% \\
\end{array}$ & $\begin{array}{c}\text { Moderate } \\
13 \% \\
\end{array}$ & $\begin{array}{c}\text { Moderate to } \\
\text { high } \\
33 \% \\
\end{array}$ & $\begin{array}{l}\text { High } \\
54 \%\end{array}$ \\
\hline $\begin{array}{l}\text { 6. Estimate the average hours per week that you worked on your } \\
\text { Clinic Project (including in-class and out of class): }\end{array}$ & $\begin{array}{c}3 \text { to } 6 \text { hours } \\
16 \%\end{array}$ & $\begin{array}{c}7 \text { to } 9 \text { hours } \\
52 \% \\
\end{array}$ & $\begin{array}{c}10 \text { to } 12 \\
\text { hours } \\
26 \%\end{array}$ & $\begin{array}{c}13 \text { to } 15 \\
\text { hours } \\
3 \%\end{array}$ & $\begin{array}{c}\text { Over } 16 \\
\text { hours } \\
3 \%\end{array}$ \\
\hline 7. Assess the effectiveness of your team. & $\begin{array}{c}\text { Dysfunctional } \\
0 \% \\
\end{array}$ & $\begin{array}{c}\text { Somewhat } \\
\text { dysfunctional } \\
15 \%\end{array}$ & $\begin{array}{l}\text { OK } \\
17 \%\end{array}$ & $\begin{array}{c}\text { Somewhat } \\
\text { functional } \\
32 \%\end{array}$ & $\begin{array}{c}\text { Very } \\
\text { functional } \\
36 \% \\
\end{array}$ \\
\hline 8. What is your overall rating of this course? & $\begin{array}{l}\text { Poor } \\
0 \%\end{array}$ & $\begin{array}{l}\text { Fair } \\
3 \%\end{array}$ & $\begin{array}{c}\text { Average } \\
21 \%\end{array}$ & $\begin{array}{l}\text { Good } \\
27 \%\end{array}$ & $\begin{array}{l}\text { Excellent } \\
\qquad 49 \%\end{array}$ \\
\hline
\end{tabular}


Table 4. Selected questions and survey results for Venture Capital Fund Projects conducted within the Junior/Senior Engineering Clinic.

\begin{tabular}{|c|c|c|c|c|c|}
\hline \multirow{3}{*}{$\begin{array}{l}\text { Question } \\
\begin{array}{l}\text { 1. To what degree were the technical skills learned in your major } \\
\text { coursework used effectively in your projects? }\end{array}\end{array}$} & \multicolumn{5}{|c|}{ Rating Scale c and Results } \\
\hline & Ineffectively & $\begin{array}{l}\text { Effectively to } \\
\text { Moderately }\end{array}$ & Moderately & Effectively & $\begin{array}{c}\text { Very } \\
\text { Effectively }\end{array}$ \\
\hline & $0 \%$ & $0 \%$ & $20 \%$ & $45 \%$ & $35 \%$ \\
\hline \multirow[t]{2}{*}{$\begin{array}{l}\text { 2. How many engineering disciplines were required to complete } \\
\text { your project? }\end{array}$} & $\begin{array}{l}\text { Within one } \\
\text { discipline }\end{array}$ & $\begin{array}{l}\text { Mostly within } \\
\text { one discipline }\end{array}$ & $\begin{array}{l}\text { Two } \\
\text { Disciplines }\end{array}$ & $\begin{array}{l}\text { Three } \\
\text { Disciplines }\end{array}$ & $\begin{array}{l}\text { Four } \\
\text { Disciplines }\end{array}$ \\
\hline & $3 \%$ & $20 \%$ & $52 \%$ & $20 \%$ & $5 \%$ \\
\hline \multirow[t]{2}{*}{$\begin{array}{l}\text { 3. What is the probability that your engineering clinic project } \\
\text { could be the basis for a new process or product? }\end{array}$} & Low & $\begin{array}{l}\text { Low to } \\
\text { average }\end{array}$ & Average & $\begin{array}{l}\text { Average to } \\
\text { high }\end{array}$ & High \\
\hline & $3 \%$ & $3 \%$ & $8 \%$ & $31 \%$ & $56 \%$ \\
\hline \multirow[t]{2}{*}{$\begin{array}{l}\text { 4. Assess your leadership and project management skills: } \\
\text { a. Before taking this course }\end{array}$} & Poor & Fair & Average & Good & Excellent \\
\hline & $3 \%$ & $6 \%$ & $49 \%$ & $42 \%$ & $0 \%$ \\
\hline \multirow[t]{2}{*}{ b. After taking this course. } & Poor & Fair & Average & Good & Excellent \\
\hline & $0 \%$ & $0 \%$ & $18 \%$ & $62 \%$ & $21 \%$ \\
\hline \multirow[t]{2}{*}{$\begin{array}{l}\text { 5. Assess your effort expended on the following activities: } \\
\text { a. Literature review / Research }\end{array}$} & & $\begin{array}{l}\text { Low to } \\
\text { moderate }\end{array}$ & Moderate & $\begin{array}{l}\text { Moderate to } \\
\text { high }\end{array}$ & High \\
\hline & $18 \%$ & $21 \%$ & $26 \%$ & $33 \%$ & $3 \%$ \\
\hline \multirow[t]{2}{*}{ b. Application of engineering theory and/or design calculations. } & Low & $\begin{array}{l}\text { Low to } \\
\text { moderate }\end{array}$ & Moderate & $\begin{array}{l}\text { Moderate to } \\
\text { high }\end{array}$ & High \\
\hline & $0 \%$ & $3 \%$ & $10 \%$ & $49 \%$ & $38 \%$ \\
\hline \multirow[t]{2}{*}{$\begin{array}{l}\text { c. Use of advanced engineering software (Pro/E, Fluent, } \\
\text { HYSYS, etc.) }\end{array}$} & Low & $\begin{array}{l}\text { Low to } \\
\text { moderate }\end{array}$ & Moderate & $\begin{array}{l}\text { Moderate to } \\
\text { high }\end{array}$ & High \\
\hline & $0 \%$ & $3 \%$ & $13 \%$ & $33 \%$ & $51 \%$ \\
\hline \multirow[t]{2}{*}{ d. Laboratory experiments and/or fabrication and testing } & Low & $\begin{array}{l}\text { Low to } \\
\text { moderate }\end{array}$ & Moderate & $\begin{array}{l}\text { Moderate to } \\
\text { high }\end{array}$ & High \\
\hline & $0 \%$ & $0 \%$ & $10 \%$ & $21 \%$ & $69 \%$ \\
\hline \multirow[t]{2}{*}{ e. Creative thinking and problem solving } & & $\begin{array}{l}\text { Low to } \\
\text { moderate }\end{array}$ & Moderate & $\begin{array}{l}\text { Moderate to } \\
\text { high }\end{array}$ & High \\
\hline & $0 \%$ & $0 \%$ & $10 \%$ & $18 \%$ & $72 \%$ \\
\hline \multirow[t]{2}{*}{$\begin{array}{l}\text { 6. Estimate the average hours per week that you worked on your } \\
\text { Clinic Project (including in-class and out of class): }\end{array}$} & 3 to 6 hours & 7 to 9 hours & $\begin{array}{l}10 \text { to } 12 \\
\text { hours }\end{array}$ & $\begin{array}{l}13 \text { to } 15 \\
\text { hours }\end{array}$ & $\begin{array}{l}\text { Over } 16 \\
\text { hours }\end{array}$ \\
\hline & $0 \%$ & $13 \%$ & $64 \%$ & $21 \%$ & $3 \%$ \\
\hline 7. Assess the effectiveness of your team. & $\begin{array}{c}\text { Dysfunctional } \\
0 \% \\
\end{array}$ & $\begin{array}{c}\text { Somewhat } \\
\text { dysfunctional } \\
3 \% \\
\end{array}$ & $\begin{array}{l}\text { OK } \\
8 \% \\
\end{array}$ & $\begin{array}{c}\text { Somewhat } \\
\text { functional } \\
36 \% \\
\end{array}$ & $\begin{array}{c}\text { Very } \\
\text { functional } \\
54 \% \\
\end{array}$ \\
\hline \multirow[t]{2}{*}{ 8. What is your overall rating of this course? } & Poor & Fair & Average & Good & Excellent \\
\hline & $0 \%$ & $0 \%$ & $5 \%$ & $23 \%$ & $72 \%$ \\
\hline
\end{tabular}

Question 1 is intended to assess whether the Junior/Senior Engineering Clinic is integrated well with the coursework that each student takes concurrently within their own discipline. It also is intended to assess whether the students know how to apply their newly attained engineering science knowledge to an openended design problem. The results of both surveys show that students cannot always apply their engineering science knowledge to an open ended problem. Virtually all engineering clinic projects require technical knowledge that is beyond that which exists in a junior or senior engineering student. It is a frustrating experience for students, but one that results in their recognition for the need to engage in lifelong learning. 
Question 2 is intended to assess whether the students believe that their project required more than one discipline. The intention of the engineering clinic is that all projects are multidisciplinary to some extent. The reality is that some projects are more multidisciplinary than others. As seen in the survey of non-VCF projects, the majority of projects (53\% total) were evaluated by the students as requiring only one discipline, with perhaps some help from outside. In the case of the VCF projects, only $23 \%$ of the projects were evaluated by the students as requiring mostly one discipline. By their assessment, 52\% of the projects required two disciplines and $25 \%$ required a contribution by three or more disciplines to complete. This result shows that the VCF projects are more effective than the average project in satisfying one of the major objectives of the Engineering Clinic, which is to demonstrate the ability to work effectively in a multidisciplinary team. It should be noted, however, that to obtain VCF funding a team is required to have students from more than one discipline.

Question 3 is intended to assess the degree to which the students can recognize the commercial potential of their project. It also assesses if the students recognize the "big picture" and the degree to which they are beginning to think like entrepreneurs. The results of this question were encouraging in both sets of data. In the non-VCF surveys, $55 \%$ of respondents suggested that their engineering clinic project had an average/high or high probability of forming the basis for a new product. For the VCF projects, this total jumps to a total of $87 \%$. It should be noted that all VCF projects are aimed at the development of a new product or process, so this figure should be $100 \%$. However, in some cases, after working on a project for a semester or two, some students find that their product is not commercially feasible. In either case, this result shows that the VCF projects are more effective than the average project in satisfying one another major objectives of the Engineering Clinic, which is to demonstrate entrepreneurial skills.

Question 4 assesses how their project has helped students to develop better project management skills. Both sets of data show that the engineering clinic helps students to learn project management skills. Indeed, one of the major stumbling blocks for VCF project leaders is to put together a solid team and to delegate responsibility. Delegating responsibility is not always easy for the project leader, since the project was usually his or her brainchild. By necessity, however, the students learn to delegate responsibility in order to complete the project. In the VCF projects, $58 \%$ of the students evaluated themselves as having poor to average management skills at the start of the project, while only $18 \%$ evaluated themselves as having poor to average management skills after completion of the project.

Question 5 assesses which type of technical skills were required to complete their project. Question 5a shows that the VCF students responded that they actually spent less time on literature review and research than the non-VCF students. This question should, however, be reworded to include patent searches. By requirement, $100 \%$ of all VCF students spend a significant effort performing patent searches.

Questions 5b and 5c show an interesting and perhaps unexpected result. The VCF students tend to expend more of an effort applying engineering theory, design calculations and using advanced engineering software than their non-VCF counterparts. While it was recognized that product development projects would be technically challenging, it was not expected that these projects would necessarily require more of a technical effort than the average clinic project. As will be shown below in the amount of hours per week expended, the VCF students are generally more motivated than their counterparts. 
Indeed, perhaps the most significant result of this study is that ownership is an effective motivator.

Question 5d shows that all engineering clinic projects are laboratory intensive. This is not only a major objective of the engineering clinic, but one of the hallmarks of the College of Engineering at Rowan University.

Question 5e shows that all engineering clinic projects require a high degree of creative thinking and problem solving. This is particularly true for the VCF projects. An overwhelming $90 \%$ of respondents reported that the VCF projects required a high or moderate to high amount of creative problem solving. Once again, this is a major objective of the engineering clinic and VCF projects are quite effective in satisfying this objective.

Question 6 assesses exactly how much time the students devoted to their project per week. The Junior/Senior Engineering Clinic formally meets 6 hours per week, but it is expected that students devote approximately 10 hours per week total to their projects. In VCF projects, $88 \%$ of respondents reported that they work more than 10 hours per week versus $42 \%$ for the non- VCF projects. As stated above, students who work on the VCF projects are generally more motivated than the average engineering clinic student. This is not altogether unexpected since, generally, only motivated students decide to submit proposals for VCF funding. However, these are precisely the students who should be rewarded and allowed to work on projects of their own invention. It is precisely this ownership that results in students working longer hours and utilizing a higher degree of technical expertise to complete their projects.

Since all work in the engineering clinic is accomplished by teamwork, Question 7 assesses how functional teams were in accomplishing the task at hand. Generally, the VCF projects reported fewer problems with dysfunctional teams. This result might be affected by the requirement that VCF project leaders select their own team members. However, once again, it also is a function of the ownership that these students have in their project.

Finally, as in all course evaluation surveys, the students are asked in Question 8 to evaluate the course as a whole. Generally speaking, students rate the Junior/Senior Engineering Clinic high. Since its inception in Fall 1998, the Junior/Senior Engineering Clinic has become part of the fabric and culture of the College of Engineering at Rowan University. One of the mottoes that our students have developed is, "If you are not in class, you are in clinic." Working hard in the clinic is expected and, for the most part, enjoyed. In terms of the VCF projects, this is particularly true with $95 \%$ of respondents rating the overall course as Good or Excellent.

In summary, the results of the assessment survey show that VCF projects are extremely effective in satisfying the objectives of the Junior/Senior Engineering Clinic. While it is understood that this survey is slightly skewed by the fact that the VCF projects are generally populated by the more motivated students, the results suggest that providing a venue for students to work on their own original ideas is an effective way to get students to work hard and to apply their technical expertise toward creative problem solving. The students who work on VCF projects are given much autonomy and, since the projects are their own original idea, they generally take ownership from day one. The assessment data is supported by the following student comments: 
- $\quad$ "...we feel that our semester in Junior Engineering Clinic was a wonderful experience. This project has allowed us to gain experience in many new and interesting areas."

- "We feel extremely fortunate to have been able to participate in a one hundred percent independent research project. It gave us the opportunity to work on our own, under your advice."

- " I can say that I have learned more in this clinic than in a previous engineering course."

- "We strongly recommend the entrepreneurial option to all other engineering students."

\section{Conclusions and Future Challenges}

\section{Student Participation}

The activities described herein were funded by three separate grants from the NCIIA. In the first year of the project (Fall '98/Spring '99), only two teams applied to the VCF and only one team was funded. In Fall '99, 8 teams were awarded VCF projects. Our experience has shown that, while many students have ideas for original inventions, the majority of the students do not have the motivation to formalize these ideas into a solid proposal. This was a surprise at first, given what we believed to be significant incentives of funding and team autonomy. In the Fall '99 semester we were delighted at the number of students who expressed a desire to work on an original product development project. A major reason for the change in student attitudes is that, having observed the initial team in action, many others were motivated to propose their own ideas. In short, the word has spread among the students. After 5 semesters of supporting VCF projects, a steady-state participation level of 2 to 4 projects per semester is anticipated.

\section{No Cost Extensions}

The original plan for the VCF projects required that all work be completed in one semester. In some cases, this has been possible but in many cases no-cost extensions have been granted to the student teams to continue work for a second semester. However, each individual department at Rowan has the power to remove a student from a project if the project is failing to meet the proper educational requirements. To date, this has not occurred.

Faculty "Buy In"

Ultimately, the VCF cannot be successful without a cadre of faculty willing to "buy in" to the concept. Faculty members are needed to help encourage invention within their traditional coursework and be willing to supervise students if they propose original inventions. Initially, there may have been a hesitancy to participate in this endeavor for several reasons. Firstly, there appears to be an inherent misconception that all inventions are electromechanical widgets. This misconception arises from the vision of the inventor as Thomas Edison tinkering in his laboratory. The reality is that the U.S. Patent Office issues utility patents for biotechnology, computer software, and chemical processes as well as electronic and mechanical devices. Secondly, even if faculty members understand the wide variety of potential inventions, they often see themselves as researchers, not inventors. Fortunately, the word has spread among faculty members as well. To date, 9 out of 30 faculty members within the College of Engineering have supervised VCF projects.

\section{Gender}

During the period of this study, the population of women students in Rowan Engineering was 
approximately 15 to $20 \%$, slightly below national norms. Furthermore, 7 out of our 30 faculty members (as well as our Dean) are women. However, during this period no proposals have been written by women and out of the 39 total participants, only two were women. This result is potentially alarming and should be examined further.

\section{Graduation}

One of the issues that is faced in each of the VCF projects is that, upon graduation these students are extremely marketable. To date, none of our graduating seniors have continued work on their project after graduation, choosing instead to accept employment or attend graduate school. It is hoped that the current plan for a high tech business incubator on campus might provide the support necessary for a graduating student who wishes to bring their concept to market.

\section{Acknowledgments}

The VCF has been supported by NCIIA grants 142-98, 203-98, and 312-99. Resources used in this project were supported in part by NSF under the grants DUE-9751651 and DUE-9850563. Special thanks to students Clay Emerson, Chris Burg, Megan Matricardi, Mike Hayden, Greg Rueblinger, Brian Fitzpatrick, Mark Farwell, Jason Childs, Jason Daniel, Sam Greenfeld, Doug Gabauer, Anthony Docimo, Robert Jones, Harry Wiedman, Mike Ciocco, Dave Bowen, Glen Roames, Mike Jensen, Brian Kuritz and Matt Johnson for providing information on the individual projects.

\section{References}

1. Jahan, K., Hesketh, R. P., Schmalzel, J. L. and Marchese, A. J. (2001). "Design and Research Across the Curriculum: The Rowan Engineering Clinics.” International Conference on Engineering Design. Glasgow, Scotland, 2001.

2. Schmalzel, J. L., Marchese, A. J., Mariappan, J., and Mandayam, S. (1998). "The Engineering Clinic: A Four-Year Design Sequence.” 2nd Annual Conference of National Collegiate Invention and Innovation Alliance, Washington, DC.

3. Marchese, A. J., Mandayam, S., Chen, J. C., and Schmalzel, J. L (2000). "Reinventing the Design Curriculum." 4th Annual Conference of National Collegiate Invention and Innovation Alliance, Washington, DC.

4. Marchese, A. J., Chandrupatla, T. R., Schmalzel, J. L., and Mandayam, S. (1999). "A Venture Capital Fund to Encourage Rapid Product Development with Multidisciplinary Teams in the Junior Engineering Clinic." Proc. Conf. Amer. Soc. Eng. Edu, Charlotte, NC.

5. Marchese, A. J., Schmalzel, J. L., Chen, J. C., Chandrupatla, T.R., Dahm, K., Mandayam, S. A., Ramachandran, R. P. and von Lockette, P. (2000). "The NCIIA Venture Capital Fund at Rowan University." Proc. Conf. Amer. Soc. Eng. Edu, St. Louis, MO. 